\title{
Evolution of the instantaneous flow structure in gas-solid fluidized beds
}

\author{
Xiaoyang Wei ${ }^{1}$, Jiangshan $\mathrm{Liu}^{1}$, Chengxiu Wang ${ }^{2}$, and Jesse Zhu ${ }^{3}$ \\ ${ }^{1}$ Western University \\ ${ }^{2}$ China University of Petroleum Beijing State Key Laboratory of Heavy Oil Processing \\ ${ }^{3}$ The University of Western Ontario
}

May 5, 2020

\begin{abstract}
Gas-solid fluidized beds have been widely used as reactors in the industry. Per the operations, fluidized beds can be classified as bubbling fluidized bed (BFB), turbulent fluidized bed (TFB), circulating turbulent fluidized bed (CTFB), circulating fluidized bed riser (CFB riser) and circulating fluidized bed downer (CFB downer). For fluidized beds, the instantaneous flow structure determines the overall performances. However, in the literature, the instantaneous flow structure remains lacking for TFB, CTFB, high-density CFB riser and high-density CFB downer. As a result, the evolution of the instantaneous flow structure in fluidized beds has not been well studied. In this work, instantaneous flow information in fluidized beds was acquired using an optical fiber probe. Then, according to the phase characteristics, instantaneous flow structures were demarcated as the "dilute structure" and "dense structure". Finally, the evolution of instantaneous flow structures is, for the time, thoroughly discussed for gas-solid fluidization.
\end{abstract}

\section{Hosted file}

FlowStructures_Various fluidized bed.docx available at https://authorea.com/users/301597/ articles/431489-evolution-of-the-instantaneous-flow-structure-in-gas-solid-fluidizedbeds 